\title{
Acute clouding of trifocal lens during implantation: a case report
}

\author{
Qian Liu, Suhua Zhang ${ }^{*}$ Xiaogang Wang, Weifang Cao and Yading Jia
}

\begin{abstract}
Background: Intraoperative IOLs clouding of several kinds of hydrophilic acrylic intraocular lenses (IOLs) have been reported due to temperature changes. This phenomenon reported previously occurred in cold countries and during the winter months. However, no clinical case was reported about trifocal IOL opacification during operation. We report a case in which acute opacification of the optical region occurred simultaneously when AT LISA tri 839mp(Carl Zeiss) was implanted into the eye.

Case presentation: A 79-year-old woman with a cortex and nucleus cataract was scheduled to undergo right eye phacoemulsification assisted by femtosecond technique. The trifocal lens (AT LISA tri 839mp), which is made of hydrophilic acrylic (25\%) with hydrophobic surface properties, was chosen for implantation. As the IOL was implanted into the eye, it became cloudy immediately. Then it was replaced by another AT LISA tri 839mp, which was transferred from lens company outside, the same phenomenon was observed. These two lenses underwent the same temperature fluctuation from cold outside to operating room. Finally, a ZCBO0 (Allergan) was implanted.
\end{abstract}

Conclusions: The acute intraoperative clouding of trifocal lens(AT LISA tri 839mp) results from fluctuation of temperature should be noticed.

Keywords: AT LISA tri 839mp, Opacification, Cloudy

\section{Background}

The major hydrophilic acrylic intraocular lenses(IOLs) that have been reported on regarding postoperative opacification include Hydroview (Bausch\& Lomb), SC60B-OUV (Medical Developmental Research, Inc.), ACRL-60 (Ophthalmed, LLC), Memory Lens (Ciba Vision), AquaSense (Ophthalmic Innovations International, Inc.), and Akreos Adapt AO (Bausch \& Lomb) [1-6]. Delayed opacification of IOLs is known as pseudocataract $[7,8]$. Intraoperative acute clouding of acrylic hydrophilic IOLs has been reported [9]. There have been no reports of intraoperative acute clouding with the AT LISA tri $839 \mathrm{mp}$.

\section{Case presentation}

To meet patient expectations of high-quality postoperative vision, including distant, medium, and near vision, a 79-year-old woman with a cortex and nucleus cataract was scheduled to undergo right eye phacoemulsification

* Correspondence: zhanggsuhua@126.com

Shanxi Eye Hospital, No. 100 Fudong Street, Taiyuan, Shanxi 030002, People's Republic of China assisted by femtosecond laser technique with $\mathrm{a}+18.5 \mathrm{di}-$ opter trifocal IOL(AT LISA tri 839mp, Carl Zeiss)implantation. Her preoperative best-corrected visual acuity was $\log$ MAR 0.3 .

In this patient, we routinely used perioperative regimen of mydriasis by tropicamide 4 times every $10 \mathrm{~min}$, superficial anesthesia by proparacaine 4 times, Medical Sodium Hyaluronate Gel(17 mg/ml, Bausch\& Lomb), and compound chloride perfusate. After lens fragmentation using femtosecond laser, phacoemulsification was uneventful and carried out under topical anesthesia. The IOL was transparent before implantation (Fig. 1). However, as soon as the optical region was implanted into the eye, it became cloudy (Fig. 2), and remained cloudy without alleviation (Fig. 3) for $1 \mathrm{~h}$ in vivo(Waiting for the second +18.5D AT LISA tri $839 \mathrm{mp}$,we observed whether the clouding IOL would be clear). The IOL was removed using small incision on the sclera. We try another AT LISA tri $839 \mathrm{mp}$ lens, which was transferred from local company outside, The temperature outside was about $-3{ }^{\circ} \mathrm{C}$. The IOL had been in the theater for about $10 \mathrm{~min}$ before 


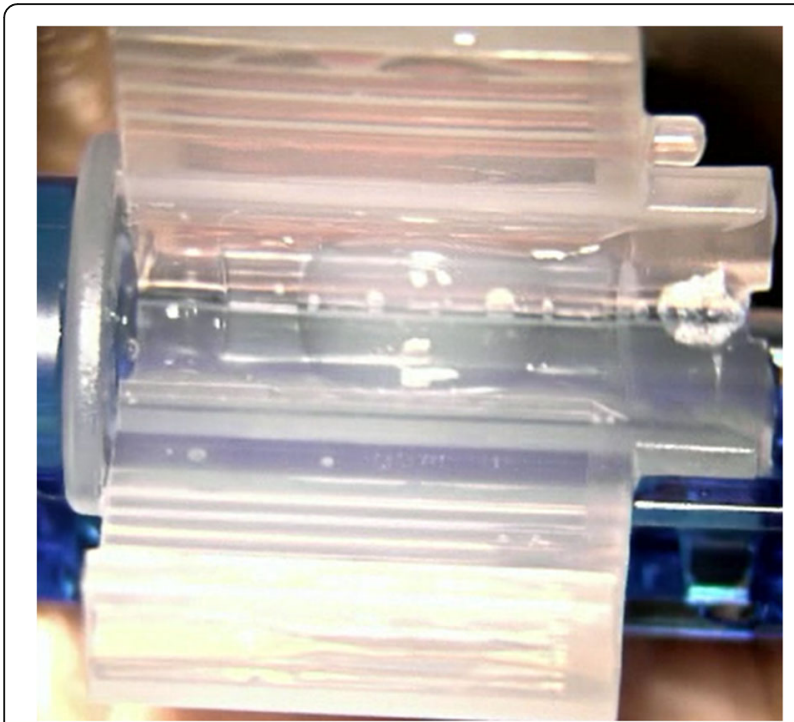

Fig. 1 AT LISA tri $839 \mathrm{mp}$ is tansparent before implantation

implantation into the eye. The same phenomenon occurred (Fig. 4), the IOL kept cloudy for $8 \mathrm{~min}$ in vivo then moved out. It became transparent 5 min later in vitro (Fig. 5). After acquiring of the patient's informed consent, a ZCB00(Allergan) was finally implanted for safety. The post operative day 1 uncorrected visual acuity was $\log$ MAR 0.1 ,best corrected visual acuity was also $\log$ MAR 0.1 .

\section{Discussion}

To meet the ever increasing demand of vision quality, more and more high-end IOLs were applied in refractive

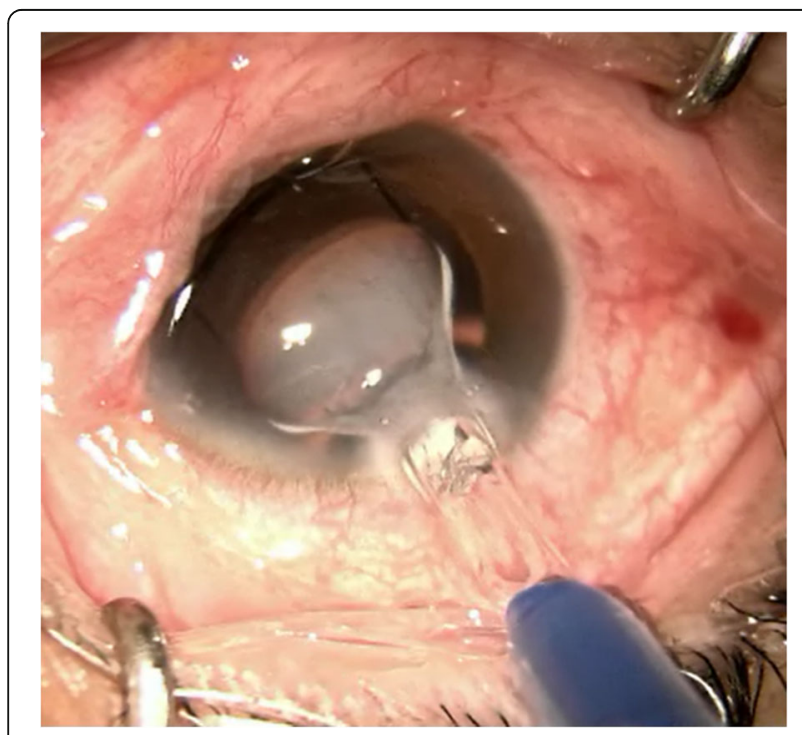

Fig. 2 The optical region was cloulding immediately as soon as implanted into eye

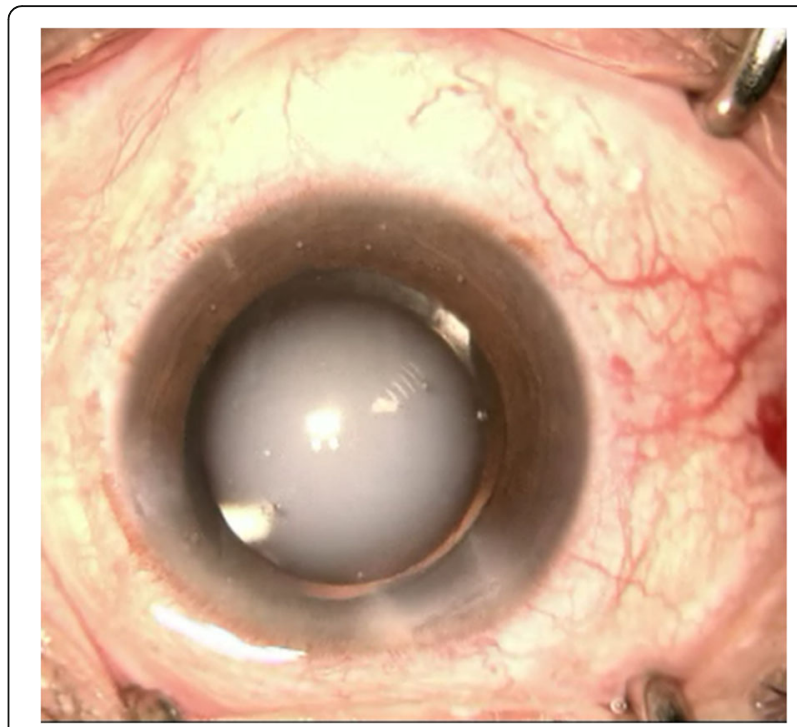

Fig. 3 The first IOL kept cloudy persistently without alleviation for $1 \mathrm{~h}$ in vivo

cataract surgery. AT LISA tri $839 \mathrm{mp}$, as a kind of trifocal IOLs, could provide distant, medium, and near vision.

Femtosecond laser technology has the ability to facilitate and optimize manual portions of cataract surgery [10-12]. Zhang S [13] reported that inflammatory cytokines IL-1 $\beta$, IL-6, and PGE2 significantly increased after femtosecond laser-assisted cataract surgery. However, to the best of our knowledge, there was no report about IOL opacification caused by femtosecond laser and correlative inflammatory cytokines.

Different from the lenses (hydrophilic acrylic) that were previously reported to become cloudy in vivo, AT

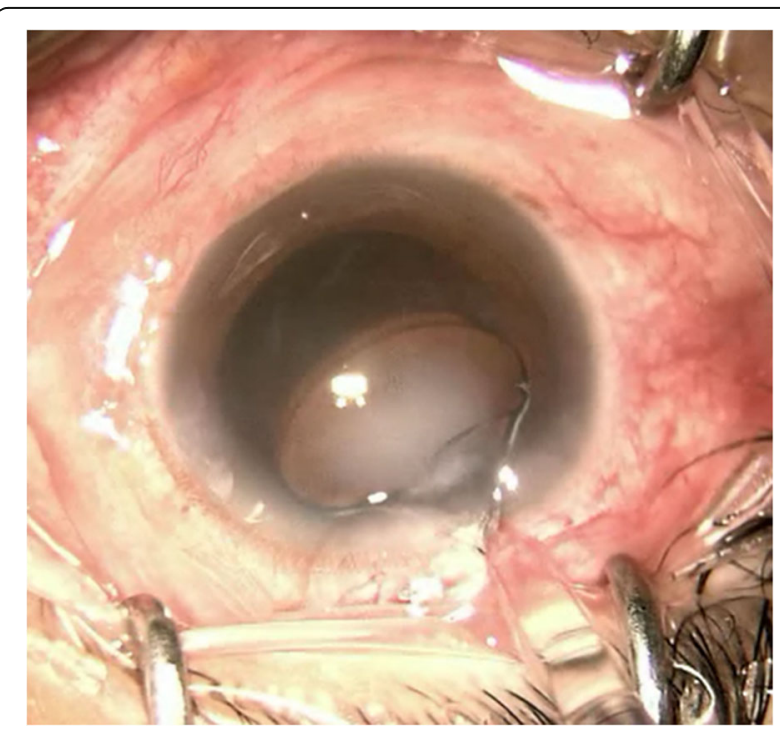

Fig. 4 The second AT LISA tri 839mp turned cloudy immediately as implanted into eye 


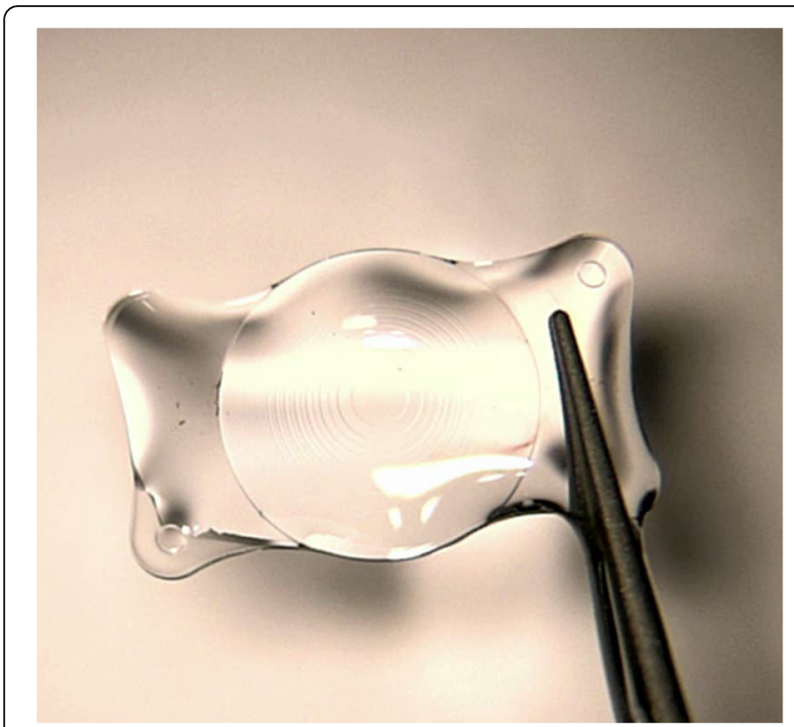

Fig. 5 The second IOL became partially transpearent 5 min after explantation

LISA tri $839 \mathrm{mp}$ IOL is made up of hydrophilic acrylic (25\%) with hydrophobic surface properties. As Yu AK reported, the pseudocataracts occurred spontaneously due to calcium and phosphate accumulation, which resulted in hydroxyapatite crystal formation [14]. The surface of this trifocal IOL is made of hydrophobic acrylic, and the opacification appeared immediately after implantation, which may not cause any chemical, mechanical, or geometric change to the IOL polymer.

Similar to the report by Pallavi Tyagi [9], the IOL we used was delivered to the theater (about $20{ }^{\circ} \mathrm{C}$ ) shortly before the procedure from the store located outside the premises. The outdoor temperature was about $-3{ }^{\circ} \mathrm{C}$. The IOL had been in the theater for only15 min before implantation into the eye. The opaqueness in Pallavi Tyagi's report lasted for about $3 \mathrm{~h}$ then cleared, and the opacification reported by Sezer Helvacı [15] disappeared by the following day. The first AT LISA tri $839 \mathrm{mp}$ remained cloudy without alleviation for about $1 \mathrm{~h}$,then moved out. The second one became opacified again as soon as the optical region implanted into the eye. However, $5 \mathrm{~min}$ after the second IOL was moved out, it became clear. The two IOLs underwent the same temperature changes. Moreover, the manufacturer's manual mentioned that opacification can occur due to a change in temperature. We deduced that the change of temperature caused the opacification of AT LISA tri $839 \mathrm{mp}$ in this report.

\section{Conclusion}

The acute intraoperative clouding of trifocal lens (AT LISA tri $839 \mathrm{mp}$ ) was caused by fluctuation of temperature in a short time. Therefore, we suggest that the IOL's temperature should be kept in normal range as manufacture's guideline requested $\left(2-45{ }^{\circ} \mathrm{C}\right)$ before implantation. This may avoid IOL acute clouding caused by abrupt change of temperature (less than $2{ }^{\circ} \mathrm{C}$ to anterior chamber temperature) during implantation especially during winter season in the countries in temperate or polar zone.

\section{Abbreviations}

IL-1 ß: Interleukin-1 beta; IL-6: Interleukin-6; IOL: Intraocular lens; IOLs: Intraocular lenses; logMAR: Logarithm of Mininal Angle Resolution; PGE2: Prostaglandin E2

\section{Acknowledgements \\ Not applicable.}

\section{Funding}

None

\section{Availability of data and materials}

The datasets during and/or analyzed during the current study available from the corresponding author on reasonable request.

\section{Authors' contributions}

ZSH made contributions to conception of the manuscript, revising it, and performing the surgery. LQ made contributions to design of the manuscript, acquisition, analysis and interpretation of data, and drafted the manuscript. WXG,CWF made substantial contributions to acquisition, analysis and interpretation of data. JYD made contributions to revising the manuscript critically for important intellectual content. All of the authors have revised the manuscript. All authors read and approved the final manuscript.

Ethics approval and consent to participate

The study was approved by the ethics committee of Shanxi Eye Hospital.

\section{Consent for publication}

Written informed consent was obtained from the patient for publication of this case report and any accompanying images.Copies of the written consent are available for review by the Editor of this journal.

\section{Competing interests}

The authors declare that they have no competing interests.

\section{Publisher's Note}

Springer Nature remains neutral with regard to jurisdictional claims in published maps and institutional affiliations.

Received: 12 July 2017 Accepted: 28 November 2017

Published online: 08 December 2017

\section{References}

1. Izak AM, Werner L, Pandey SK. Calcification of modern foldable hydrogel intraocular lens designs. Eye (Lond). 2003;17(3):393-406.

2. Neuhann IM, Werner L, Izak AM. Late postoperative opacification of a hydrophilic acrylic (hydrogel) intraocular lens: a clinic opathological analysis of 106 explants. Ophthalmology. 2004;111(11):2094-101.

3. Pandey SK, Werner L, Apple DJ. Calcium precipitation on the optical surfaces of a foldable intraocular lens: a clinicopathological correlation. Arch Ophthalmol. 2002;120(3):391-3.

4. Tehrani M, Mamalis N, Wallin T. Late postoperative opacification of MemoryLens hydrophilic acrylic intraocular lenses: case series and review. J Cataract Refract Surg. 2004;30(1):115-22.

5. Lee CE, Kim YC, Chang SD. Opacification of the optic of an Akreos adapt intraocular lens. Korean J Ophthalmol. 2010;24(6):371-3.

6. Cao D, Zhang H, Yang C. Akreos Adapt AO Intraocular lens opacification after vitrectomy in a diabetic patient: a case report and review of the literature. BMC Ophthalmol. 2016;16:82. doi: 10.1186/s12886-016-0268-3.

7. Taşkapilı M, Kocabora S, Kandemir N. Göziçi mercek kesifleșmesi olan gözlerde değişim cerrahisi sonuçları. Glo-Kat. 2008;3(1):15-9. 
8. Özçetin H, Akova B, Toprak A. Psödokatarakt olgularımızda klinik. T Oft Gaz. 2006;36:229-33.

9. Tyagi P, Shah N, Jabir M. Intraoperative clouding of a posterior chamber intraocular lens. Int Ophthalmol. 2011;31(6):483-4.

10. Palanker DV, Blumenkranz MS, Andersen D. Femtosecond laser-assisted cataract surgery with integrated optical coherence tomography. Sci Transl Med 2010. Nov 17;2(58):58ra85.

11. Nagy Z, Takacs A, Filkorn T. Initial clinical evaluation of an intraocular femtosecond laser in cataract surgery. J Refract Surg. 2009;25(12):1053-60.

12. He L, Sheehy K, Culbertson W. Femtosecond laser-assisted cataract surgery. Curr Opin Ophthalmol. 2011;22(1):43-52.

13. Wang $L$, Zhang $Z$, Koch DD. Anterior chamber interleukin $1 \beta$, interleukin 6 and prostaglandin E2 in patients undergoing femtosecondlaser-assisted cataract surgery. Br J Ophthalmol. 2016;100(4):579-82.

14. AK Y, Shek TW. Hydroxyapatite formatiın on implanted hydrogel intraocular lenses. Arch Ophthalmol. 2001;119(4):611-4.

15. Helvacı S. Acute opacification of hydrophobic acrylic intraocular lens during implantation:result of temperature variation. Arq Bras Oftalmol. 2015;78(4): 267.

Submit your next manuscript to BioMed Central and we will help you at every step:

- We accept pre-submission inquiries

- Our selector tool helps you to find the most relevant journal

- We provide round the clock customer support

- Convenient online submission

- Thorough peer review

- Inclusion in PubMed and all major indexing services

- Maximum visibility for your research

Submit your manuscript at www.biomedcentral.com/submit 